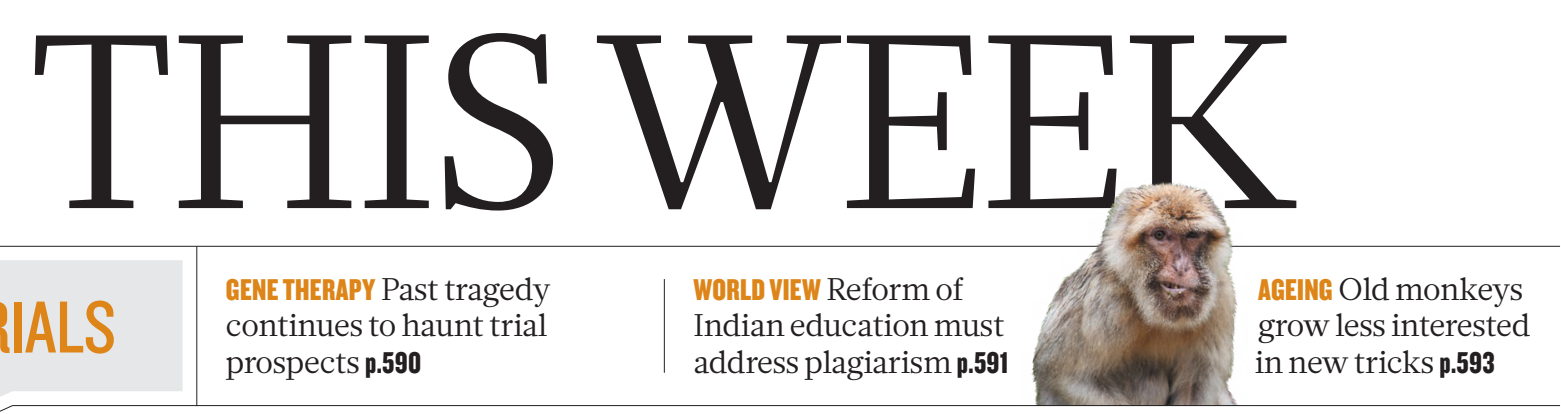

\section{EDITORIALS} prospects $\mathbf{p} . \mathbf{5 9 0}$
Indian education must address plagiarism $\mathbf{p . 5 9 1}$ grow less interested

in new tricks $\mathbf{p} . \mathbf{5 9 3}$

\title{
Non-expert nation
}

\section{Scientists - just like everybody else - have little idea what will happen now that the United Kingdom has voted to exit the European Union.}

$\mathrm{P}$ sychologists who have studied the peculiar phenomenon of buyer regret - the second thoughts that follow the purchase of a shiny new car, say - note a curious paradox. The more effort that consumers put into making their decision, the more information they seek and the more they weigh up the options, the more likely they are to want to change their mind later.

Just how much careful thought the people of the United Kingdom put into last week's decision to quit the European Union is currently a matter of some debate. But if the prominent examples of buyer regret among people who voted 'Leave' and now want to 'Remain' are any guide, it may have been more than many critics think.

Psychologists might conclude that Kelvin Mackenzie, the former editor and now columnist of The Sun newspaper, must have been weighing up the options very carefully indeed when he wrote his " 10 reasons why you must vote Brexit" the week before the crucial vote. How else to explain his U-turn, a few days after $52 \%$ of voters heeded his demand, when he admitted: "I have buyer's remorse. A sense of be careful what you wish for. To be truthful I am fearful of what lies ahead."

Scientists in the United Kingdom and elsewhere share his anxiety and fear. Hundreds have responded to calls from this journal to express their feelings, and the overwhelming question that they have replied with is: what happens now?

UK politicians who pushed for the country to exit the EU have gone to ground. A similar silence reigns in the European Commission's research directorate. Commission sources mutter darkly, and only off the record, of 'uncharted territories' and 'needing time' to consider the many issues that will arise. UK politicians and the research directorate declined to engage before the vote with the 'what if' question, at least publicly. So it is no surprise that scientists have been left with the feeling that no one had planned for the Brexit eventuality. What will be the status of those from other EU countries doing their $\mathrm{PhDs}$ or postdoctoral research in the United Kingdom? What will happen to the EU-funded research collaborations that are led from the United Kingdom?

What do we know for sure? Some of the most familiar European research facilities are not creatures of the EU, so will remain fundamentally unaffected by Brexit. These include the European particle-physics laboratory CERN, the European Molecular Biology Laboratory and the European Space Agency.

More recently, the European Commission has found a way to steer the creation of other, much-needed Europe-wide research infrastructures through an umbrella structure called ESFRI (European Strategy Forum on Research Infrastructures) that helps to foster intergovernmental agreements in which it has no fundamental role.

Some research infrastructures are based on a particular legal framework that stipulates that the host country must be a member state. For the European Spallation Source, headquartered in Sweden, and the Biobanking and BioMolecular resources Research Infrastructure headquartered in Austria, nothing changes. For the European Social

Survey and the structural-biology infrastructure known as Instruct, both headquartered in the United Kingdom, Brexit means that new arrangements will have to be made; internal talks have already begun.

Talks on similar agreements for core European Commission scientific activities won't start until the United Kingdom formally declares

"Scientists have been left with the feeling that no one hadplanned for the Brexit eventuality."

\section{likely to damage the prospects of so many who voted for it.}

If the United Kingdom does trigger article 50, research facilities owned by the commission and stationed in the country, such as the nuclear-fusion facility JET, face an uncertain future. And until a new agreement is made, UK scientists will be shut out of the EU's multibillion-euro Horizon 2020 programme - including its prestigious European Research Council granting body, from which the United Kingdom benefits more than any other country, by a wide margin.

Michael Gove, a senior figure in the Leave camp, notoriously claimed during the campaign that the United Kingdom has "had enough of experts". He has got his wish, but he should beware: buyer regret is not available to those who did the selling. I SEE NEWS P.597

\section{The big picture}

\section{Interdisciplinary research is vital if we are to meet the diverse needs of modern society.}

$\mathrm{T}$ To tackle society's challenges through research requires the engagement of multiple disciplines. For two examples, in responding to the challenges of climate change and of social progress, see the Comment articles on pages 613 and 616, respectively.

To highlight the issues that arise in such research, imagine an integrated project to determine the causes of destructive risk-taking in inner-city adolescents and to identify appropriate interventions. Such a programme might combine disciplines ranging from anthropology, sociology, psychology, law, economics and ethics to psychiatry, health systems, urban design and developmental neurobiology.

To frame the research challenge, and to design interventions that will be effective in targeted neighbourhoods, academic researchers need to work with non-academic partners to understand the needs 